Vol. 20(2011): 119-130.

\title{
Policy harmonized approach for the EU agricultural sector modelling
}

Guna Salputra $^{1 *}$, Frédéric Chantreuil2 ${ }^{2}$ Kevin Hanrahan ${ }^{3}$, Trevor Donnellan ${ }^{3}$, Myrna van Leeuwen ${ }^{4}$ and Emil Erjavec ${ }^{5}$

${ }^{1}$ Latvian State Institute of Agrarian Economics (LSIAE), Struktoru 14, LV-1039, Riga, Latvia,

${ }^{2}$ INRA, 4 allée Adolphe Bobierre, CS 61103, 35011 Rennes cedex, France,

${ }^{3}$ Rural Economy Research Centre (RERC), Teagasc, Athenry, Co. Galway, Ireland,

${ }^{4}$ LEI, Alexanderveld 5, 2585 DB Den Haag, The Netherlands,

${ }^{5}$ University of Ljubljana (LJUB), Groblje 3, 1230 Domzale, Slovenia,

*e-mailguna@lvaei.lv

Policy harmonized $(\mathrm{PH})$ approach allows for the quantitative assessment of the impact of various elements of EU CAP direct support schemes, where the production effects of direct payments are accounted through reaction prices formed by producer price and policy price add-ons. Using the AGMEMOD model the impacts of two possible EU agricultural policy scenarios upon beef production have been analysed - full decoupling with a switch from historical to regional Single Payment scheme or alternatively with re-distribution of country direct payment envelopes via introduction of EU-wide flat area payment. The PH approach, by systematizing and harmonizing the management and use of policy data, ensures that projected differential policy impacts arising from changes in common EU policies reflect the likely actual differential impact as opposed to differences in how "common" policies are implemented within analytical models. In the second section of the paper the AGMEMOD model's structure is explained. The policy harmonized evaluation method is presented in the third section. Results from an application of the $\mathrm{PH}$ approach are presented and discussed in the paper's penultimate section, while section 5 concludes.

Key-words: modelling, CAP, direct support, decoupling, policy evaluation 
Salputra, G. et al. Policy harmonized approach for the EU agricultural sector modelling

\section{Introduction}

The European Union's Common Agricultural Policy (CAP) and the sectoral modelling of agriculture in the EU are closely intertwined in the literature. EU decision makers have traditionally used the results of a wide range of quantitative tools in framing their choices among alternative policy instruments. Quantitative assessments of the impact of policy changes and policy effectiveness can be catalysts for public debate. Through the provision of quantitative analysis of alternative policies such economic research influences the direction and tone of policy debates by defining the quantitative range of possible future alternatives (Bartosova et al. 2008).

Since its origins, the CAP has been under constant internal and external reform pressures (Yrjölä et al. 2001; Garzon 2006; Swinnen 2008). The 1992 MacSharry CAP reform, in an attempt to arrest growing production and budgetary costs, introduced direct payments to the CAP. These direct payments were introduced as compensation for income losses expected to result from reduced intervention prices. Expenditure on such compensatory direct payments, in subsequent reforms described as coupled payments or premiums, was limited by restrictions on the total number of premiums claims allowable per Member State. The pattern of intervention price reductions being "compensated" for by increases in coupled direct payments was again observed in the 2000 reforms when the decisions on increases in the value of direct payments and reductions in intervention prices were adopted by the European Council along with an agreement on the multi-year EU budgetary programme called Agenda 2000 (Daugbjerg et al. 2007).

The Fischler reform in 2003 changed the form of CAP direct income support payments by introducing decoupled direct income supports, though it largely preserved the scope and distribution of funds across Member States and types of agricultural holdings (Swinnen 2008). Policy modifications under the CAP Health Check (HC) agreement of 2008 followed the direction established in 2003 by further decoupling direct payments, increasing the rate at which payments are modulated and al- lowing Member States to switch from historical to regional flat area payment regimes. Despite the almost continuous reform process the pressure for further CAP reform has not abated, with the upcoming EU Budget review likely to lead to further agricultural policy change in the medium term.

Within the parameters of the 2003 Fischler reform (and subsequent CAP Health Check agreement) EU Member States have some flexibility in the degree to which they must decouple direct payments and in the choice of model used to implement the decoupled Single Payment (SP) scheme. The Old Member States (OMS) can implement the SP scheme by either granting historical support level to farmers or using a regional flat area payment direct income support scheme. OMS also have some flexibility in the degree to which the link between production and receipt of direct income support is retained. The New Member States (NMS) are still allowed to use the transition support system - Single Area Payment (SAP) scheme - one of the advantages of which is the flexibility to provide national top-ups to agriculture in coupled and decoupled forms until 2013 in line with phasing-in of EU direct payments, while EU support within SAP scheme must be totally decoupled. Thus the accession of NMS in 2004 and 2007, when combined with the Fischler reforms of 2003, introduced a considerable degree of policy heterogeneity to the CAP by comparison to Agenda 2000 policy framework.

In line with the $\mathrm{HC}$ decisions, the diverse agricultural policy systems permissible under the CAP may be gradually equalized over the period 2010 to 2013 through the mandatory decoupling of direct payments that under the Fischler reforms could be retained by Member States as coupled direct payments and by the voluntary switch from historical SP schemes to a regional SP scheme in OMS.

The effects of the decoupling of direct payments have been analysed for the arable crop sector using the Policy Evaluation Model (PEM) developed at OECD (2006). The implementation of increasingly diverse and complex policies in European agriculture argues for the linking of models from different disciplines that operate across different spatial and other analytic scales. The resulting model 
Vol. 20(2011): 119-130.

conglomerates have the advantage of being able to exploit the synergies of diverse methodological approaches and tools (Britz et al. 2008). However, Esposti (2008) in a review of recent model based economic analysis of the CAP concluded that the long-term perspective of CAP after the year 2013 at the EU27 level, in the dimensions being currently publicly discussed (Buckwell 2007; Swinnen 2008; Begg et al. 2008; ECORYS 2008), and even the current shape of CAP under its different schemes, is not completely and systematically covered in any model application, because the existing modelling approaches may still miss the correct representation of some detail of the policy itself. These deficiencies are largely due to the heterogeneity and complexity of the current CAP system as well as the nature of the questions posed by the possible future development of the CAP.

Considering the analytic challenges faced, a unified methodological approach that allows for quantitative assessments of the impact of various elements of dynamic CAP direct support systems is required (Salputra et al. 2007). Such an analytical approach was developed as the Policy harmonized evaluation for the AGMEMOD agricultural partial equilibrium sector model ${ }^{1}$ that allows for the systematic examination of the impact of existing direct support policies as well as those proposed and expected in the future. Using the AGMEMOD model, the aim of this paper is to demonstrate the usefulness of the $\mathrm{PH}$ approach to the economic analysis of agricultural policy changes in the sector modelling.

\footnotetext{
${ }^{1}$ The AGMEMOD model was developed under the auspices of two FP projects the FP6 project "Agricultural Member States Modelling for the EU and Eastern European Countries (AGMEMOD 2020)" and the FP5 project "Agricultural Sector in the EU Member States and Newly Associated States in Central and Eastern Europe (AG-MEMOD)". See Chantreuil et al. (2005) and Salamon et.al. (2008) for further details.
}

\section{The AGMEMOD partial equilibrium sector model}

The AGMEMOD model is a dynamic, multi-product partial equilibrium model. The modelling strategy used is to build an EU aggregate model by combining separate country models, where commodity market sub-models are the basic components in each country-level model. The commodity market submodels endogenously determine supply and demand, international trade and prices. Each country model captures the behavioural response of economic agents (farmers/producers and consumers/users) to changes in prices, exogenous macroeconomic variables and policy instruments, as well as the response to the previous years' outcome according to the dynamic structure of the model. Model's parameters are mostly econometrically estimated, however, considering limited opportunity for econometric estimations due to data constraints in NMS, synthetic or calibrated parameters are applied as well. Using the parameters, exogenous data and lagged endogenous data, it is possible to generate projections for the model's endogenous variables over a set of alternative policy scenarios, for a given projection period. The model is solved with endogenous prices balancing supply and use of each modelled commodity at both Member State and EU27 levels. Price linkage equations are used to capture the relationships between market clearing prices in Member State and EU markets, and between the EU market and the Rest of the World market. Greater detail on the AGMEMOD modelling approach can be found in Erjavec et al. (2006), Chantreuil et al. (2005) and Bartova et al. (2008).

As in econometric approach the AGMEMOD model's evaluation of policy change is based on the reaction of agri-food markets to other policy and market changes during the sample period over which the model's parameters were estimated. When the original AGMEMOD model was developed in FP5 project the main analytic focus was on the responses of agricultural supply and demand to changes in key European market prices and changes in the value of coupled direct payments. 
Salputra, G. et al. Policy harmonized approach for the EU agricultural sector modelling

Beginning with the MacSharry reforms of 1992, the CAP evolved with a focus on production related direct support (payments per area and per animal head). Up until 2004, the modelling approach used to examine CAP support under "Agenda 2000" was in general also appropriate for the evaluation of policies in the NMS. In these countries pre-accession support was mostly coupled to agricultural production, crop area or animals. Following the 2003 Fischler reform and the enlargement of the EU in 2004 direct income support to farmers was made available without an obligation to produce a specific volume of production. This change necessitated some changes in how the effect of agricultural policy on production was modelled and led to the development of the policy harmonized evaluation approach.
As the motivation for production, in a common market such as the EU, depends not only on the direct support system applied by an individual country, but also on the support system applied by other countries, all of the different types of direct payments that were allowed under the CAP were included in the structure of the AGMEMOD model through the implementation of the policy harmonized approach. Under the $\mathrm{PH}$ approach these direct payments were recalculated in the form of policy add-ons to market prices increasing the margin between the producer price and input costs. CAP market support has an impact on EU prices affecting supply-demand balance and external trade. The modelling structure used in the AGMEMOD model is reflected in.

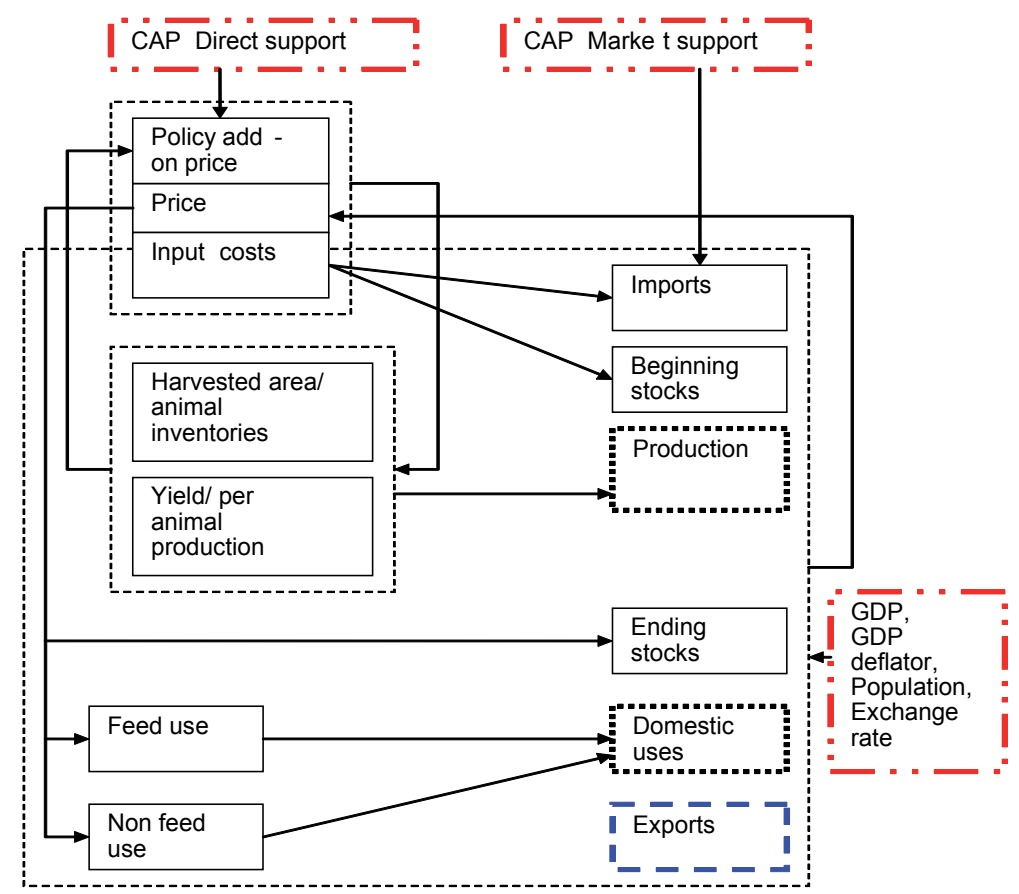

Legend

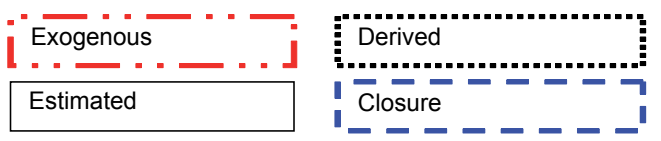

Fig.1. General modelling structure of AGMEMOD model. Source: AGMEMOD Partnership. 
Vol. 20(2011): 119-130.

\section{Policy harmonized evaluation approach}

OECD studies have identified three channels through which government support policies affect production - market effects, risk effects, and dynamic effects, which can occur simultaneously and are cumulative (OECD 2006). The methodological basis for the grouping of direct support measures under different systems used in this paper is the two way classification of support applied by the OECD (2008) in the calculation of its Producer Support Estimates (PSE):

- Coupled support - payments based on output, on area planted or animal numbers where production is required;

- Decoupled support - payments based on non-current area and the number of animals where production is required or not required (historical entitlements).

Decoupled payments as a concept are interpreted differently by economists and decision-makers. The theoretical assumption that decoupled payments do not have production, market and redistributive effects has many advocates, but also many opponents (Conforti 2005). The assertion that decoupled payments do not affect production should hold in the event of production neutrality and when markets are complete. However, Key and Roberts (2008) list numerous studies (USDA 2003; USDA 2004), which establish that in the event of incomplete markets, decoupled payments can have production effects. These effects are, according to the literature cited by Key et al. (2008), insignificant on average, but could have important consequences for the structure of individual agricultural holdings. Decoupled payments affect production decisions in the following ways (Bhaskar et al. 2007): they affect the producers' risks, i.e. they either decrease the level of risk non-benevolence ("wealth effects") or they reduce the risk ("insurance effects"), alleviate the conditions for obtaining loans, affect the decisions in allocation of labour on agricultural holdings, change the value of land, rents and prices of land, and affect production decisions in view of expected payments. Cumulatively these effects, together with the effects of remaining coupled payments, could have important production effects.

In the implementation of the $\mathrm{PH}$ approach within the AGMEMOD model all direct payments are recalculated as a policy price add-on to the relevant producer price to form a reaction price. These policy based price add-ons are used in the assessment of the impact of total budgetary support on agricultural production. The reaction price accounts for the effect of decoupled direct payments through the application of coefficients - the multipliers, which adjust the share of budgetary support in the reaction price. It is assumed that support related to a product or production factor associated with a particular product has a direct impact on production. Support granted to land, irrespective of the type of product produced, can also act as a stimulating factor. The magnitude of the multipliers applied to different types of decoupled subsidies depends on the nature of these support payments.

The value of the regional multiplier is set equal to 0.3 and the value of the historical multiplier is set equal to 0.5 . They are assumed based on OECD (2006) results. The historical payment provides a greater production incentive than the regional payment since the appropriate production technologies have already been established on farms. If the payment is fully coupled to production then the multiplier used is set equal to 1 .

Reaction price, when deflated by input costs indices is the economic variable that drives the supply decisions of farmers within the model's structure incorporating both the policy and market based signals to producers. Thus the supply response of farmers to decoupled payment is positive and changes in the value of decoupled payments will lead to responses by farmers that are analogous to but smaller than farmers' responses to changes in agricultural output prices. The similar effects of decoupled payments have been discovered by Gohin (2008), Rude (2008) and Balkhausen et.al (2007).

To make the AGMEMOD model capable of incorporating the switches in agricultural policy regimes, first, all applicable direct support measures that form part of the CAP (under the 2003 
Salputra, G. et al. Policy harmonized approach for the EU agricultural sector modelling

CAP reform and the more recent $\mathrm{HC}$ decisions) are implemented in the policy block through the envelopes which reflect the total amount of budgetary resources allocated to the sector (see Fig. 2). The links between different policy measures in the model ensure that the evaluation of policy changes involving switches between policy schemes (historical to regional) and changes in the objects of policy, e.g. the switch from per animal direct payments to per hectare supports are feasible. Second, in each country model equations were added that calculate the country specific reaction prices. Final$1 y$, the equations on the supply sides of each of the country level commodity sub-models, where the reaction prices should be used, were specified.

The first set of equations allocates, Member State by Member State, the Pillar I budget between different types of envelopes (coupled, historical and regional). This set of equations is formulated in the same way for all countries and is implemented at the level of the combined AGMEMOD model. The reaction prices for a commodity $\mathrm{j}$ are simulated as endogenous variables. The policy price add-on adjusts depending on assumptions made concerning exogenous policy input variables. These exoge- nous policy variables include modulation, coupling rates and multipliers, as well as variables controlling the allocation of budgetary envelopes between coupled payments, regional and historical payment schemes. The relationship between AGMEMOD policy variables and the various CAP instruments are set out in the following equations.

Effective national envelope of 1st Pillar direct payments $e n v_{t}$ is a part of National ceiling remaining after reduction by the effective modulation rate calculated according to the farm structure in each country:

$$
e n v_{t}=E N V_{t} \cdot\left(1-c m o_{t}-v m o_{t}\right)
$$

where $E N V_{t}$ is National ceiling defined by Regulations of European Commission, $\mathrm{Cmo}_{t}$ is compulsory modulation rate and $v m o_{t}$ is voluntary modulation rate.

The ceiling for total coupled payments envelope $c p t_{t}$ is limited by premiums $\mathrm{p}$ for commodity $\mathrm{j} \operatorname{com}_{j}$, maximum coupling rates defined for each premium $\mathrm{p}$ and commodity $\mathrm{j} \mathrm{crt}_{t}^{p}$; and country specific reference numbers for each premium $\mathrm{p}$ and commodity $\mathrm{j} r e f_{j}^{p}$.

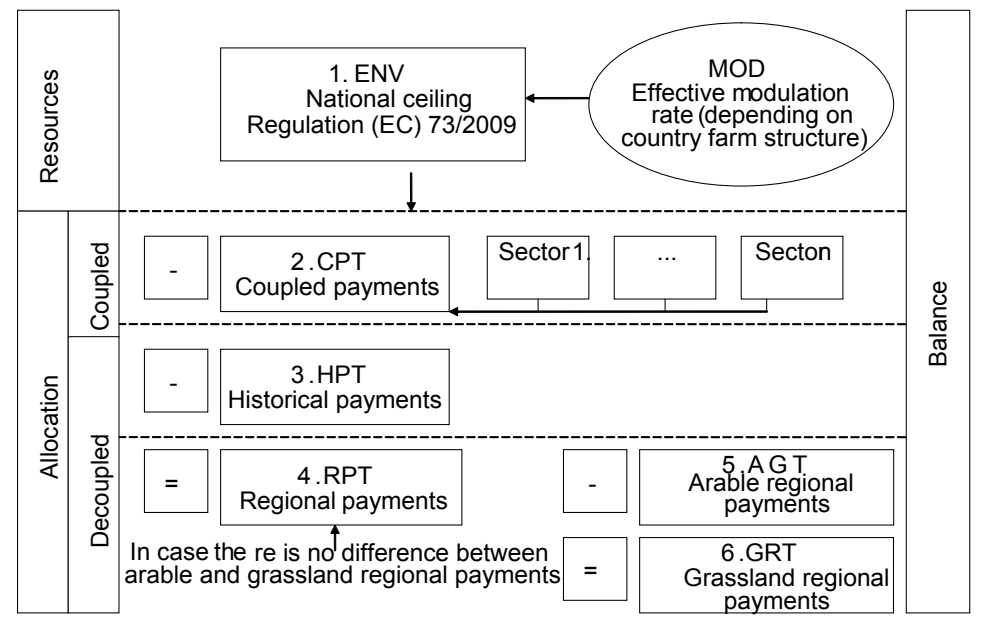

Fig.2. Allocation of total direct support. 
Vol. 20(2011): 119-130.

$$
\begin{aligned}
& c p t_{t}=\sum_{p=1}^{s}\left[\sum_{j=1}^{l^{\prime}}\left(\mathrm{crt}_{t j}^{p} \cdot \operatorname{com}_{j}^{p} \cdot r e f_{j}^{p}\right)\right. \\
& \left.+\sum_{j=l^{\prime}+1}^{l}\left(\mathrm{crt}_{t j}^{p} \cdot \operatorname{com}_{j}^{p} \cdot y d r_{j} \cdot a h r_{j}^{p}\right) \cdot\left(1-c m o_{t}-v m o_{t}\right)\right] \\
& j=\overline{1, l^{\prime}} ; \overline{l^{\prime}+1, l, l} ; p=1, \ldots, s ;
\end{aligned}
$$

Reference numbers for premium $\mathrm{p}$ are defined for livestock products and by reference areas and reference yields for crop products $j=\overline{l^{\prime}+1, l}$

Decoupled historical payments $h p t$ :

$h p t_{t}=E N V_{t} \cdot h r t_{t} \cdot\left(1-c m o_{t}-v m o_{t}\right)$

where $h r t_{t}$ is a share of historical payments in national ceiling chosen by each country.

Decoupled regional payments $r p t_{t}$ :

$$
r p t_{t}=e n v_{t}-c p t_{t}-h p t_{t}, \forall t
$$

The second set of equations that are added in the implementation of the policy harmonization approach within the AGMEMOD model is country specific and is implemented in the country models directly. These equations calculate the policy addons to be included in reaction prices which are then used as explanatory variable in supply side equations of the country level AGMEMOD models. In following equations we present the specifications for arable crops and meat. Policy price add-on for arable crop j is modelled as

$$
\begin{aligned}
& \operatorname{prc}_{t j}=\left(c p m \cdot c p t_{t j} / \max \left(a h r_{t j}, a h_{t-1 j}\right)\right. \\
& \left.+\left(h p m \cdot h p t_{t}+r p m \cdot r p t_{t}\right) / a h_{t-1}\right) / \text { yield }_{t-1, j}
\end{aligned}
$$

where cpm, hpm, rpm are multipliers of coupled, historical and regional payments defining the weight of impact of different type of direct payments on production decisions. Policy add-on for meat $\mathrm{i}$ :

$$
\begin{aligned}
& p r c_{t j}=\left(c p m \cdot c p t_{t j} / c c t_{t-1, j}\right. \\
& \left.+\left(h p m \cdot h p t_{t}+r p m \cdot r p t_{t}\right) / a h_{t-1} / u t r_{t-1}\right) / s l w_{t j}
\end{aligned}
$$

where $u t r$ is average livestock density.

\section{Application of the methodology - policy scenarios results}

The use of the PH approach in the AGMEMOD model allows us to define and analyse detailed policy scenarios that involve changes to CAP policy instruments such as modulation rates, coupled direct payments values, budgetary shares of regional and historical SP schemes.

Under the terms of the 2008 CAP Health Check agreement the degree of decoupling of direct payments will be deepened with the full decoupling of the direct payments that, in some Member States, remained coupled under the 2003 Fischler reforms. The HC agreement also includes a provision for a voluntary move by OMS that currently apply the historical payment scheme to a regional flat area payment system. The policy environment set out in the $\mathrm{HC}$ with its incorporation of possible SP scheme regime switches, increases in modulation rates or redirection of certain amount of Pillar I funds for specific country rural, environmental and quality support; and decoupling of remaining coupled direct payments can be analysed using the AGMEMOD model with its PH component. In the broader sense with respect of rural development and review of other studies $\mathrm{HC}$ has been recently analysed by Nowicki et.al (2009). More radical reform scenarios than those agreed in the recent Health Check can also be analysed. Such scenario analysis illustrates the usefulness of the $\mathrm{PH}$ approach as well as allowing for an assessment of the effects of agreed and possible future policy changes on individual Member States.

To illustrate the capacity of the $\mathrm{PH}$ approach as implemented within the AGMEMOD model we specify Baseline and two alternative scenarios:

- Baseline scenario - which involves the continuation of policy as agreed under the HC. Under the Baseline the mix of historic, regional, and dynamic hybrid direct aid schemes with coupled payments (where EU Member States have chosen them) will continue along with the mandatory elements of the Health Check decisions implemented through to the end of 
Salputra, G. et al. Policy harmonized approach for the EU agricultural sector modelling

the projection period in 2020. Rates of modulation are increased, milk quota and set aside are abolished, and direct supports related to production are to be fully decoupled with the exception of some beef and sheep payments. The additional funds raised through the increase in the rate of modulation are used to fund Pillar II measures and thus reduce the effective national envelopes. The CAP budget National ceilings remain at their current level.

- Regional Flat Rate (RFR) scenario - this scenario assumes that all Member States currently using a historical payment model move to a regional flat area payment model from 2010 onwards, with the transition to this regional payment model occurring through a series of three annual changes in the total value of existing entitlements. The annual reductions in the total value of historical entitlements will be 25 percent in the first year and 50 percent of the rest of historical envelope in the second year. In the third year national flat area payments are assumed to be implemented, where these are defined as the National ceilings divided the total eligible area. In addition all coupled payments that remain under the $\mathrm{HC}$ agreement are assumed to be fully decoupled;

- European Union Flat Rate (EUFR) scenario - this scenario assumes that an EU wide flat regional rate payment will be introduced instead of the historical and various Member State specific regional payment models. The EU flat area payment rate per hectare is set at the level of the average per hectare entitlement in 2014 (the first year following the completion of the transition period for those Member States that acceded to the EU in 2004). This rate 247 EUR/ha is calculated as the sum of all Member States' National Ceilings in 2014 divided by the sum of all Member States' eligible areas according to the EUROSTAT data. All other agricultural policies are the same as those applying under the RFR scenario, i.e. all coupled direct payments are fully decoupled.

In this paper analysis focuses on the results for a selection of Member States that represent the range of different implementations of direct support schemes within the EU-27: France - a Member State which retained the maximum number of coupled payments and applied the historical SP scheme; Finland - a Member State that retained some coupled payments but applied the hybrid dynamics SP scheme (where the payment scheme changes from the historical to the regional scheme by 2013); Ireland: a Member State that retained no coupled payments but applied the historical payment scheme; Latvia - a Member State applying the SAP scheme with coupled Complementary National Direct Payments (CNDP). Only results for the beef sectors in the individual Member States are presented. Bureau et al. (2008) among others have identified the EU beef sector as particularly vulnerable to policy reform. This and the widespread prevalence of coupled direct payments that are linked to beef production under the current CAP motivates our analytic focus on this sector. Full details of the impact on other commodity markets and other Member States impacts are available from the authors.

Table 1 presents the Baseline projections of beef producer prices, the value of the beef policy add-on, beef reaction price and projections for beef production in France, Finland, Ireland and Latvia. The policy add-on to beef prices incorporates all of the different coupled cattle payments and decoupled historical and regional payments that affect cattle production in EU Member States as adjusted by the historical and regional payment multipliers.

For France existing coupled payments for suckler cows and cattle slaughter premiums as well as decoupled historical payments are incorporated in the supply inducing policy add-on. In Ireland only the decoupled historical payments contribute to the policy add-on given the absence of any coupled direct payments. In Finland coupled male bovine premiums and the dynamic decoupled payments, with a declining share of historical and increasing share of regional payments, are included. For Latvia the coupled CNDP for suckler cows and slaughter premiums, as well as the decoupled regional payments are incorporated in the supply inducing policy price add-on $\mathrm{c}$. 
Vol. 20(2011): 119-130.

In 2008 the policy price add-on in each of the four countries adds up to $20 \%$ of the beef producer price to the reaction price. Under the Baseline the decrease in the value of the policy price add-on in Finland between 2008 and 2020 arises because of the shift from a historical to regional payment model that occurs under the Finnish hybrid SP model and the compulsory decoupling of special male premium agreed under the Health Check. In Latvia the decrease in the value of the policy add-on for beef is due to the phasing out of the coupled CNDP. These payments are totally phased out by 2012 in all of the member states that joined the EU in 2004. Given that under the Baseline no change occurs in the SP model used in Ireland and that all direct payments in Ireland were decoupled under the 2003 Fischler reform, as expected, the policy add-on does not change under the Baseline between 2008 and 2020. There are no changes also for France due to the reason that disappearance of coupled slaughter premiums is compensated by emerging availability of significant amounts of decoupled arable crops premiums. Producer price developments reflect the past tendencies and elasticities in connection with EU market, country selfsufficiency level and quality of beef.

Despite the projected increase in the Latvia beef price under the Baseline, the reduction in the policy price add-on and increases in the costs of production augmented by ongoing increases in dairy cow yields, leads to a decline in total Latvian beef pro- duction. Comparing with other countries analysed, dairy herd in Latvia is of exceptional dominance as even increasing share of suckler cows in total number of cows in 2020 is projected to comprise only $11 \%$. In Finland, where suckler cow beef production (as in Latvia) is of limited importance, the decline in the policy add-on when combined with increased costs and declining dairy cow numbers offsets the positive market price impact on total beef production. By 2020, under the Baseline, production is projection to decline by almost 15 percent compared with 2008. In Ireland, despite the constant nominal value of the policy add-on over the Baseline projection period, production of beef in Ireland declines. This arises due to projected decrease in cattle prices, declines in dairy cow numbers and increases in production costs over the projection period. In France, under the Baseline, the more or less constant policy add-on in combination with increased beef producer prices leads to a small increase in production. This result illustrates the role the positive effect of the remaining coupled premiums in France on beef production. In addition French dairy cow numbers following the removal of milk quota do not decline by as much as in Ireland.

Scenario results presented in Table 2 show the effect of the analysed policy changes on beef production and prices. The main policy change under RFR scenario is the decoupling of all direct payments and the switch from historical to regional

Table 1. Baseline scenario results for beef.

\begin{tabular}{|c|c|c|c|c|c|}
\hline & & $\begin{array}{c}\text { Beef producer price, } \\
\text { EUR } / 100 \mathrm{~kg} \\
(1)\end{array}$ & $\begin{array}{c}\text { Policy add-on, } \\
\text { EUR/100 kg } \\
(2)\end{array}$ & $\begin{array}{c}\text { Beef reaction price, } \\
\text { EUR } / 100 \mathrm{~kg} \\
(3)=(1)+(2)\end{array}$ & $\begin{array}{c}\text { Beef production, } \\
1000 \mathrm{t}\end{array}$ \\
\hline \multirow[t]{2}{*}{ France } & 2008 & 160 & 29 & 189 & 1462 \\
\hline & 2020 & 179 & 30 & 209 & 1533 \\
\hline \multirow[t]{2}{*}{ Ireland } & 2008 & 173 & 24 & 197 & 554 \\
\hline & 2020 & 141 & 25 & 166 & 400 \\
\hline \multirow[t]{2}{*}{ Latvia } & 2008 & 155 & 22 & 177 & 25 \\
\hline & 2020 & 176 & 11 & 187 & 19 \\
\hline \multirow[t]{2}{*}{ Finland } & 2008 & 192 & 44 & 236 & 89 \\
\hline & 2020 & 190 & 17 & 207 & 76 \\
\hline
\end{tabular}

Source: AGMEMOD combined model, Version 4.0. 
Salputra, G. et al. Policy harmonized approach for the EU agricultural sector modelling

Table 2. Regional flat rate (RFR) and EU wide flat rate (EUFR) scenario results for beef for 2020 in \% changes.

\begin{tabular}{lcccccc}
\hline & \multicolumn{3}{c}{ 2020, RFR via Baseline } & \multicolumn{3}{c}{ 2020, EUFR via Baseline } \\
\cline { 2 - 7 } & $\begin{array}{c}\text { Beef producer } \\
\text { price }\end{array}$ & Policy add-on & $\begin{array}{c}\text { Beef } \\
\text { production }\end{array}$ & $\begin{array}{c}\text { Beef producer } \\
\text { price }\end{array}$ & Policy add-on & $\begin{array}{c}\text { Beef } \\
\text { production }\end{array}$ \\
\hline France & 5.05 & -61.50 & -10.38 & 5.51 & -66.34 & -11.46 \\
Ireland & 0.25 & -40.76 & -2.61 & -0.53 & -52.84 & -3.86 \\
Latvia & 5.59 & -4.14 & 2.73 & 6.11 & 158.92 & 11.19 \\
Finland & 0.10 & -4.13 & 0.03 & 0.13 & 0.38 & 0.08 \\
\hline
\end{tabular}

Source: AGMEMOD combined model, Version 4.0.

schemes. The EUFR scenario assumes, in addition to the decoupling of all direct payments, that all country direct payment envelopes or national ceilings are re-distributed across the EU through the payment of an EU flat area payment. Under this scenario some countries will see total budgetary support decline while others will see total budgetary support increase.

The switch from the historical to regional scheme and the decoupling of all direct payments has negative effects on French and Irish beef production. The magnitude of the negative impact on production in Ireland is smaller than in France. This is due to the fact that all direct payments in Ireland are decoupled under the Baseline, however, the negative impact appears because historical payments granted for beef producers will be equally distributed between all eligible hectars. The strong reaction of France beef producers is the result of dynamic effect in the long term following to the shock of total decoupling of payments in 2014 reinforced by switch to regional payments. The change to a regional flat area payment system is expected to have minor though positive effects on beef production in Latvia and Finland. These small positive impacts arise due to the increase in cattle prices that follows from the decline in total EU27 beef production. The negative production impact of the move to a regional payments model in France and Ireland does not arise in either Latvia or Finland since in both Member States regional payments models (the SAP scheme in the case of Latvia) are being used under the Baseline.

The introduction of an EU wide flat area payment (under the EUFR scenario) does not signifi- cantly change the level of the policy add-ons for France when compared with the outcome under the RFR scenario. This result is due to the fact that the French regional flat rate payment is very close to the average EU27 rate. The larger change in the Irish policy add-on occurs because the Irish regional flat area payment is larger than the average EU27 flat rate payment. The Finnish regional flat rate payment is marginally lower than the average EU27 rate and consequently the policy price add-on component for beef increases and this leads to a small increase in beef production relative to the Baseline. In contrast the Latvian policy price add-on increases dramatically under the EUFR scenario. The Latvian regional flat rate payment is the lowest in the EU27 and the move to a EU27 flat rate payment increases the policy price add-on by almost 160 percent. This dramatic increase gives rise to a large increase in Latvian beef production. The small scale of Latvian beef production in an EU context ensures that the large change in production in Latvia (and other EU Member States) does not negatively affect either Latvian or EU27 cattle prices, which under the EUFR scenario increase relative to the Baseline.

\section{Conclusions}

The Fischler reforms of the CAP in 2003 and the CAP Health Check of 2008 together with the upcoming EU budget review will mean that analysis of the impact of changes in agricultural policy 
Vol. 20(2011): 119-130.

at Member State and EU levels will continue to be demanded. Changes in the level of budgetary support to EU agriculture, changes in the method of distributing such budgetary support between farmers and amongst Member States, and changes in the distribution of support between Pillar I and Pillar II measures are all possible over the medium term. The policy harmonized approach presented in this paper allows for the systematic analysis of these and other agricultural policy issues at both the Member State and EU levels.

The usefulness of the PH approach has been illustrated through its implementation in the AGMEMOD model and its use in analysing a series of EU agricultural policy reform scenarios. The scenarios examined involved the full decoupling of all direct payments and a movement to a regional payment model (the RFR scenario) and the full decoupling of direct payments and the introduction of an EU wide flat area payment model (the EUFR scenario).

The complexity of these reforms scenarios in the European context arises from i) the differing nature of baseline or current agricultural policy environments that exist in different EU member states under the Common Agricultural Policy and ii) from the fact that policy changes and associated market changes in one member state can affect the market environment in other Member States.

The results presented in this paper illustrate the capacity of the policy harmonized approach (as outlined in section 3) to both reflect the complexity of the implementation of existing EU agricultural policy across different Member States and analyse changes in the EU agricultural policy environment.

The projections on the impact of both the Regional Flat rate scenario and the EU wide flat rate scenario underline the importance of the Baseline or status quo ante policy position of different member states in determining the impact of a common policy change. Because Latvia under the Baseline already has a regional flat area payment system, the Single Area Payment scheme, beef production in Latvia is only marginally affected by the move to a regional payment model. The projected growth in Latvian beef production occurs because of the increase in market prices that results from the declines in total EU beef production under the RFR scenario. The projected decline in EU production is as a result of the negative impact of the RFR on production in other Member States such as France. Under the Baseline France retains coupled beef premiums and utilises a historical decoupled payments model, as a result production of beef is projected to decline under the RFR scenario.

The large increase in Latvian beef production under the EU wide flat area payment scenario contrasts with the minor impact projected under the regional flat rate scenario. Budgetary support per hectare to Latvian agriculture under the Baseline is the lowest in the EU27 and the move to an EU wide flat rate dramatically increases the support provided to Latvian agriculture and leads to an increase in Latvian beef production. In contrast the move to an EU wide flat rate payment model under the EUFR scenario significantly reduces the budgetary support to Irish agriculture and leads to a reduction in Irish beef production.

The PH approach, by systematizing and harmonizing the management and use of policy data, ensures that projected differential policy impacts arising from changes in common EU policies reflect the likely actual differential impact as opposed to differences in how "common" policies are implemented within analytical models. However, the importance of the policy harmonized approach presented in this paper extends beyond the assurance of such analytic coherence within a specific partial equilibrium policy modelling tool such as the AGMEMOD model and could be extended to other policy modelling contexts where economic models are used in conjunction with expert knowledge on policy issues.

Acknowledgement. This work was supported by EU FP6 research funding, contract SSPE-CT-2005-021543, by contribution from partner's institutes throughout the EU and through associated projects for the Institute for Prospective and Technological Studies.

The authors would like to acknowledge the work of the AGMEMOD members and affiliates in the development of the model used for this study. 
Salputra, G. et al. Policy harmonized approach for the EU agricultural sector modelling

\section{References}

Balkhausen, O., Banse, M., \& Grethe, H. 2007. Modelling CAP Decoupling in the EU: A Comparison of Selected Simulation Models and Results. Journal of Agricultural Economics 59, 57-71.

Bartosova, D., Bartova, L., \& Fidrmuc, J. 2008. EU enlargement implications on the New Member States agri-food trade. In: 12th EAAE Congress, Ghent, Belgium. Retrieved from http://purl.umn.edu/44122

Begg, I., Sapir, A., \& Eriksson J. 2008. The Purse of the European Union: Setting priorities for the future. Occasional Papers No 2008:1, Swedish Institute for European Policy Studies.

Bhaskar, A., \& Beghin, J.C. 2007. How coupled are decoupled farm payments? A review of coupling mechanisms and the evidence. Working Papers Series No 07021, Ames, lowa State University, Department of Economics.

Britz, W., \& Heckelei, T. 2008. Recent Developments in EU Policies - Challenges for Partial Equilibrium Models. In: Modeling of Agricultural and Rural Development Policies. 107th EAAE Seminar, Sevilla, Spain. Retrieved from http://ageconsearch.umn.edu/bitstream/6315/2/ pp08br01.pdf

Buckwell, A. 2007. Next step in the CAP reform. Eurochoices, 6: 13-19.

Bureau, J.C., \& Mahé L.P. 2008. CAP reform beyond 2013: An idea for a longer view. Studies and Research No 64, Notre Europe, Paris.

Chantreuil, F., Hanrahan, K., \& Levert, F. 2005. The Luxembourg Agreement Reform of the CAP: An analysis using the AG-MEMOD composite model. Modelling Agricultural Policies: State of the Art and New Challenges, 632-652, Monte Universita Parma.

Conforti, P. 2005. The effect of direct payments of the OECD countries in world of agricultural markets. Evidence from partial and general equilibrium frameworks. Commodity and trade policy research working paper No12, FAO, Rome.

Daugbjerg, C., \& Swinbank, A. 2007. The Politics of CAP Reform: Trade Negotiations, Institutional Settings and Blame Avoidance. Journal of Common Market Studies 45: 1-22.

ECORYS. 2008. A study on EU spending. Final Report, Rotterdam, the Netherlands.

Erjavec, E., Donnellan, T., \& Kavcic, S. 2006. Outlook for CEEC agricultural markets after EU Accession. Eastern European Economics 44, 83-94.

Esposti, R. 2008. Reforming the CAP: an agenda for regional growth? In: The CAP after the Fishler reform: National implementattions, impact assessment and the agenda for future reforms. 109th EAAE Seminar, Viterbo, Italy. Retrieved from http://ageconsearch.umn.edu/
bitstream/44868/2/Espostia.pdf

Garzon, I. 2006. Reforming the Common Agricultural Policy: History of a Paradigm Change. Houndmills: Palgrave Macmillan.

Gohin, A. 2006. Assessing CAP Reform: Sensitivity of Modelling Decoupled Payments. Journal of Agricultural Economics 57, 415-440.

JRC. 2008. Bartova, L., \& M'barek, R. (ed.). Impact Analysis of CAP Reform on the Main Agricultural Commodities. AGMEMOD - Summary Report, Scientific and Technical Reports, EUR 22940 EN/1 - 2008.

Key, N., \& Roberts, M. J. 2008. Do Decoupled Payments Stimulate Production? Estimating the Effect on Program Crop Acreage Using Matching. Selected Paper at the Annual Meeting of the AAEA, Orlando, Florida.

Nowicki, P., Goba, V., Knierim, A., van Meijl, H., Banse, M., Delbaere, B., et.al. 2009 Scenar 2020-II - Update of Analysis of Prospects in the Scenar 2020 Study Contract No. 30-CE-0200286/00-21. European Commission, Directorate-General Agriculture and Rural Development, Brussels.

OECD. 2006. Decoupling agricultural support from production. Policy Brief. Retrieved from http://www.oecd.org/ dataoecd/5/54/37726496.pdf. Cited 28 March 2010.

OECD. 2008. Producers Support Estimate and related indicators of agricultural support: concepts, calculations, interpretations and use: The PSE manual. Retrieved from http://www.oecd.org/dataoecd/18/31/41121738.pdf. Cited 28 March 2010

Rude, J. 2008. Production effects of the European Union's Single Farm Payment. Canadian Journal of Agricultural Economics 56: 457-471.

Salamon, P., Chantreuil, F., Donnellan, T., Erjavec, E., Esposti, R., Hanrahan, K., et al. 2008. How to deal with the challenges of linking a large numbers of individual national models: The case of the AGMEMOD partnership. Agrarwirtschaft 57: 373-378.

Salputra, G., \& Miglavs, A. 2007. Different CAP support systems - evaluation of the impact on supply of agricultural products. Proceedings from the conference: Economic Science for Rural Development 14, 67-74. Jelgava, Latvia.

Swinnen, J.F.M. (ed.) 2008. The perfect storm - The Political Economy of the Fischler Reforms of the Common Agricultural Policy. Centre for European Policy Studies. BrusselUSDA. 2003. Burfisher, M. E., \& Hopkins, J. (ed.). Decoupled payments: household income transfers in comtemporary U.S. agriculture. Agricultural ECOnomics Reports No. 822

USDA. 2004. Burfisher, M. E., \& Hopkins, J. (ed.). Decoupled payments in a changing policy setting. Agricultural Economics Reports No. 838

Yrjölä, T., \& Kola, J. 2001. Cost-benefit analysis of multifunctional agriculture in Finnland. Contribution at the 77th EAAE Seminar / NJF Seminar No. 325. Helsinki. 